\title{
Effect of $0.12 \%$ chlorhexidine and zinc nanoparticles on the microshear bond strength of dentin with a fifth-generation adhesive
}

\author{
Homayoon Alaghehmad ${ }^{1}$, Elham Mansouri ${ }^{2}$, Behnaz Esmaili ${ }^{1}$, Ali Bijani ${ }^{3}$, \\ Sogol Nejadkarimi ${ }^{4}$, Mohsen Rahchamani ${ }^{5}$
}

Correspondence: Dr. Elham Mansouri

Email: elham_26_dnt@yahoo.com

\begin{abstract}
'Dental Materials Research Center, Department of Esthetic and Restorative Dentistry, Dental Materials Research Center, Babol University of Medical Sciences, Babol, Iran,

2Department of Esthetic and Restorative Dentistry, Babol University of Medical Sciences, Babol, Iran, ${ }^{3}$ Social Determinant of Health Research Center, Babol University of Medical Sciences, Babol, Iran, ${ }^{4}$ Department of Esthetic and Restorative Dentistry, Shahid beheshti University of Medical Sciences, Tehran, Iran,

${ }^{5}$ Doctor of Dental Surgery, Private Practice, Tehran, Iran
\end{abstract}

\section{ABSTRACT}

Objective: In this study, we compared the effects of $0.12 \%$ chlorhexidine (CHX) and nano zinc oxide (NZO) on the microshear bond strength of dentin with a fifth-generation adhesive after acid etching. Materials and Methods: Forty molar teeth were randomly divided into four main groups based on dentin surface treatment technique (a) control (single bond 2); (b) NZO; (c) CHX; and (d) NZO + CHX. In each group, half of the samples underwent thermocycling, with no thermocycling in the other half. Then, failure mode was evaluated under a stereomicroscope. Statistical analysis was performed using $t$-test, two-way ANOVA, and Chi-squared test. Results: The mean microshear bond strength of the groups without thermocycling was more than that of the groups with thermocycling, but there were no statistically significant differences between the groups with and without thermocycling in pair-wise comparisons. Conclusion: Pretreatment with NZO and CHX separately and simultaneously had no effect on the microshear bond strength of a fifth-generation adhesive.

Key words: Acid etching, bond strength, chlorhexidine, nano zinc oxide

\section{INTRODUCTION}

Lack of durability of the bond to tooth structure is one of the most important problems in the application of dental adhesive systems, especially in the etch-and-rinse adhesives. ${ }^{[1]}$ The bond to dentin is more

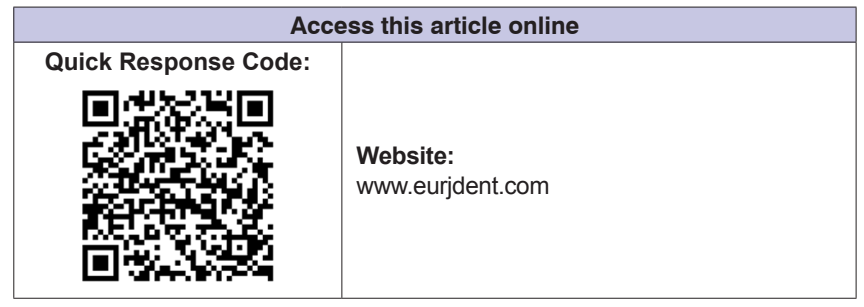

complex than that to enamel, due to its heterogeneous nature, with a larger organic content and water ${ }^{[2]}$ One problem in restorative dentistry is complete removal

This is an open access article distributed under the terms of the Creative Commons Attribution-NonCommercial-ShareAlike 3.0 License, which allows others to remix, tweak, and build upon the work non-commercially, as long as the author is credited and the new creations are licensed under the identical terms.

For reprints contact: reprints@medknow.com

How to cite this article: Alaghehmad $\mathrm{H}$, Mansouri $\mathrm{E}$, Esmaili $\mathrm{B}$, Bijani A, Nejadkarimi S, Rahchamani M. Effect of $0.12 \%$ chlorhexidine and zinc nanoparticles on the microshear bond strength of dentin with a fifth-generation adhesive. Eur J Dent 2018;12:105-10.

DOI: 10.4103/ejd.ejd_172_16 
of carious dentin. If the bacteria remain in the cavity preparation, recurrent caries might occur. ${ }^{[3,4]}$ Even, despite good seal, bacteria might be able to replicate. Bacterial growth under the restoration leads to an increase in tooth sensitivity, a decrease in its strength, recurrent caries, ${ }^{[3,4]}$ and inflammation and necrosis of the pulp. ${ }^{[5]}$ The use of disinfectant solutions such as chlorhexidine ( $\mathrm{CHX})$ is an alternative method to reduce or eliminate bacteria from cavity preparations. ${ }^{[6]}$

Recent studies have described the relationship between dentin collagen hybrid bond layer degradation and matrix metalloproteinases (MMPs) after their release by etch-and-rinse $(\mathrm{pH} \leq 4.5)^{[7]}$ and self-etch adhesives ${ }^{[8,9]}$ that can reduce the bond strength over time. ${ }^{[10]}$ It results in the creation of secondary caries and marginal discoloration, and ultimately in restoration failure. ${ }^{[8,9]}$

MMP activation is mediated by binding of $\mathrm{Zn}$ ion to $\mathrm{N}$-terminal branches. However, in two cases and by some inhibitors of the activation, function has been impaired, which might be attributed to the following reasons: (1) other enzymes and ions compete with $\mathrm{Zn}$ ion and hence deactivation occurs and (2) by increasing the amount of $\mathrm{Zn}$ ion, the other binding sites that are less likely to be activated are occupied by zinc, and by deforming the space, MMP activity is inhibited. ${ }^{[11]}$ Hitherto, the inhibitory effects of CHX, zinc, galardin, and others on MMPs activity have been studied. In addition, $\mathrm{CHX}$ can inhibit the activation of dentin MMPs even at low concentrations.

Osorio et al. ${ }^{[12]}$ investigated the effect of zinc on MMPs and deduced that zinc oxide nanoparticle, in combination with the etch-and-rinse adhesives such as single bond (SB), has the best inhibitory effect on the MMP activity, with no deleterious effect on the microtensile bond strength. Leitune et al. ${ }^{[13]}$ indicated that short applications of $\mathrm{CHX}$ at low concentrations prevent hybrid layer degradation and positively affect bond strength over time.

Alaghemand et al..$^{[1]]}$ evaluated the inhibitory effect of CHX and zinc nanoparticles on the degradation of collagen scaffolds, and in this study, we investigated the effect of CHX and zinc nanoparticles on the microshear bond strength of a fifth-generation adhesive after etching. Anti-MMP benefits of ethanol-wet-bonding were also assessed and confirmed by Sadek et al. in comparison with the use of $\mathrm{CHX}$ that is a nonspecific anti-MMP agent. ${ }^{[14]}$ The null hypotheses examined were (1) the effect of CHX and zinc nanoparticles separately and simultaneously on the microshear bond strength to dentin after acid etching with a fifth-generation adhesive is different between the test groups and is different from the control group as well. (2) adhesive failure after application of CHX and zinc nanoparticles individually and simultaneously to etched dentin is different between the test groups and is different from the control group as well.

\section{MATERIALS AND METHODS}

\section{Tooth preparation}

Forty extracted human molar teeth with no caries and no visible anatomical defects were selected. The teeth were extracted for the periodontal disease under a protocol reviewed and approved by the Ethics Committee in Babol University of Medical Sciences, Babol, Iran. The teeth were cleaned and polished by water and pumice with a brush using a low-speed handpiece. To disinfect the teeth, they were placed in $0.2 \%$ thymol solution for $24 \mathrm{~h}$, followed by storage in a saline solution until used for the purpose of the study.

The occlusal enamel was removed with a diamond bur under water and air spray perpendicular to the tooth long axis. The flat dentin surfaces were polished with 400 and 600 grit silicon carbide abrasive paper to provide a standardized smear layer. ${ }^{[15]}$

\section{Bonding procedures}

The dentin surface was etched with $37 \%$ phosphoric acid for $15 \mathrm{~s}$, rinsed for $30 \mathrm{~s}$ with tap water, and then dried with oil/water free air. The materials used are listed in Table 1.

The samples were randomly divided into four main groups $(n=10)$, based on the dentin surface pretreatment as follows:

- Group A: The control group without pretreatment. SB 2 was applied as a bonding agent to the cavity walls with a microbrush; after $10 \mathrm{~s}$ of gentle air-drying, $20 \mathrm{~s}$ of light-curing (LED VALO, Ultradent, USA) was performed at a light intensity of $600 \mathrm{~mW} / \mathrm{cm}^{2}$

- Group B: Pretreatment with nano zinc oxide (NZO). NZO powder was added to SB 2 and mixed for $1 \mathrm{~min}$ in a tube agitator (SB $2+10 \mathrm{wt} \%$ of NZO) in the dark area ${ }^{[12]}$ and applied to the cavity walls and then light-cured for $20 \mathrm{~s}$

- Group C: Pretreatment with 0.12\% CHX. CHX was used for dentine rehydrate for $30 \mathrm{~s}$ using a new microbrush until the emergence of a sleek appearance. After $60 \mathrm{~s}$, excess solution was removed with absorbent paper, ${ }^{[11]}$ and the 
Alaghehmad, et al.: Effect of $0.12 \%$ chlorhexidine and zinc nanoparticles on the bond strength of adhesive-dentin

\begin{tabular}{|c|c|c|c|}
\hline Product & Company & Ingredients & Descriptions \\
\hline Composite filtek Z 250 & $3 \mathrm{M}, \mathrm{USA}$ & $\begin{array}{l}\text { Silanated ceramic, Bis-EMA 6, UDMA, Bis-GMA, } \\
\text { TEGDMA, benzotriazole, EDMAB }\end{array}$ & Shade A2 \\
\hline Adper single bond 2 & $3 \mathrm{M}, \mathrm{USA}$ & $\begin{array}{l}\text { Ethyl alcohol, Bis-GMA, silane-treated silica (Nanofiller), HEMA, } \\
\text { copolymer of acrylic and itaconic acids, glycerol 1,3-dimethacrylate, } \\
\text { water, UDMA, diphenyliodonium hexafluorophosphate, EDMAB }\end{array}$ & $\begin{array}{l}10 \text { s gentle air drying } \\
20 \text { s curing }\end{array}$ \\
\hline Condac $37 \%$ & $\begin{array}{l}37 \text { Condac, FGM, } \\
\text { Joinville, Brazil }\end{array}$ & Aqueous-based gel containing $37 \%$ phosphoric acid & $\begin{array}{l}15 \mathrm{~s} \text { etching, } 10 \mathrm{~s} \\
\text { rinsing and drying }\end{array}$ \\
\hline Nano zinc oxide powder & Penta, Czech & & \\
\hline Chlorhexidine $0.12 \%$ & $3 \mathrm{M}, \mathrm{USA}$ & & \\
\hline
\end{tabular}
dimethacrylate, EDMAB: Ethyl 4-dimethylaminobenzoate, Bis-EMA 6: Bisphenol A polyethylene glycol diether dimethacrylate

adhesive without NZO was applied similar to the first group

- Group D: pretreatment with $0.12 \%$ CHX plus adhesive containing NZO. After using of CHX similar to Group C, adhesive (SB $2+10 \mathrm{wt} \%$ of $\mathrm{NZO}$ ) was applied similar to Group B.

In all the groups, Filtek Z250 composite resin (shade A2) was used incrementally $(1.5 \mathrm{~mm})$ on all the exposed dentin surfaces at a thickness of $4.5 \mathrm{~mm}$, and each layer was light-cured for $20 \mathrm{~s}$.

In each group, the specimens were divided into two subgroups for 2500 cycles of aging in the NEMO thermocycling machine (Mashhad, Iran) at $5^{\circ} \mathrm{C}-55^{\circ} \mathrm{C}$, with a dwell time of $30 \mathrm{~s}$ and an interval of $30 \mathrm{~s}$. Half of the samples were thermocycled and the other half was not.

\section{Microshear bond testing}

The specimens were mounted in epoxy resin. Then, the teeth were placed in a cutting machine, and each tooth was sectioned at levels of approximately $1 \mathrm{~mm} \times 1 \mathrm{~mm}$. The microshear test was performed using a universal testing machine (Zwick, Roell, Germany). A knife-edge shearing rod was used to load the specimens until fracture at a crosshead speed of $1 \mathrm{~mm} / \mathrm{min}$. Microshear bond strength was calculated in MPa from the peak load at failure divided by the specimen's surface area; the cross-sectional surface area was measured 3 times using a digital caliper (Shinwa Rules Co., Niigata, Japan) and then the mean was calculated.

After testing, the failure modes were evaluated under a stereomicroscope (Carl Zeiss Inc., Oberkochen, Germany) at $\times 10$ and classified according to the predominant mode of fracture including (1) adhesive, (2) cohesive in dentin, (3) cohesive in composite resin, and (4) mixed, i.e., a combination of adhesive and cohesive.

\section{Energy dispersive $X$-ray analysis}

Adhesive with $10 \mathrm{wt} \%$ of NZO was placed in $1 \mathrm{~mm} \times 1 \mathrm{~mm} \times 1 \mathrm{~mm}$ stainless steel quadrangular molds and light-cured using a light-curing unit for $20 \mathrm{~s}$. The samples were coated with gold, and Map-energy dispersive X-ray (EDX) analysis was performed.

\section{Statistical analysis}

Statistical analysis was performed using $t$-test to determine the level of significance, and two-way ANOVA was used for comparison between the groups. Chi-squared test was used for comparison of bond failure at the 0.05 level of significance. All statistical calculations were performed with SPSS 17.0 software (SPSS Inc., Chicago, IL).

\section{RESULTS}

The mean of microshear bond strength of the subgroups without thermocycling was higher than that of the subgroups with thermocycling, but there were no statistically significant differences between the subgroups with and without thermocycling $(P>0.05)$ [Table 2 and Figure 1].

Pair-wise comparisons did not reveal any statistically significant differences in the mean microshear bond strength values between the subgroups with and without thermocycling.

The results of failure modes are presented in Table 3. The most frequently observed failure mode was cohesive failure in all the experimental groups.

\section{DISCUSSION}

In this study, we evaluated the effect of CHX and NZO on the microshear bond strength of a fifth-generation adhesive after etching in two subgroups with and without thermocycling. 
The results showed that separate and simultaneous application of CHX and NZO had a similar effect on the microshear bond strength and failure mode. Therefore, the first and second null hypotheses were rejected.

The comparison of groups in two subgroups with and without thermocycling showed neither significant differences between the experimental groups themselves nor between these groups and the control group, which can be explained by the effect of CHX as a broad-spectrum disinfecting agent. ${ }^{[3]}$ When CHX is applied on the prepared tooth surface after acid etching, it is not washed off, and the adhesives are applied, and then, the procedure is continued. It has the potential to bind to both organic and inorganic components of the dentin. ${ }^{[16]} \mathrm{CHX}$ binds to hydroxyapatite (inorganic component) of dentin, which is believed to be mediated by the formation of a phosphate salt that leads to an increase in the surface energy of dentin, thus enhancing the dentin wetting ability of primers. The interaction of $\mathrm{CHX}$ with the organic component of dentin is believed to be mediated by binding to Type I collagen. ${ }^{[16]}$ The binding of $\mathrm{CHX}$ to the dentin matrix component is probably the best way for $\mathrm{CHX}$ to inhibit collagen bond proteases ${ }^{[17]}$ such as MMPs 2, 8, and 9. ${ }^{[8,18]} \mathrm{CHX}$ is an effective synthetic MMP inhibitor even in low concentrations $(0.02 \%-0.0001 \%) .{ }^{[18]}$ At low concentrations, the inhibitory effect of CHX on MMPs is thought to be related to a cation-chelating mechanism, wherein

\begin{tabular}{|c|c|c|c|c|}
\hline & A & B & C & D \\
\hline $\begin{array}{l}\text { Without } \\
\text { thermocycling }\end{array}$ & $15.02 \pm 4.76$ & $14.91 \pm 2.75$ & $14.4 \pm 4.06$ & $15.2 \pm 3.02$ \\
\hline $\begin{array}{l}\text { With } \\
\text { thermocycling }\end{array}$ & $13.45 \pm 4.71$ & $14.48 \pm 3.55$ & $12.52 \pm 4.14$ & $14.45 \pm 3.1$ \\
\hline
\end{tabular}

the sequestration of metal ion, such as zinc, would hamper the activation of the catalytic domains within MMPs. ${ }^{[19,20]}$ Notwithstanding the MMP inhibitory effect of CHX seems to be dose-dependent, ${ }^{[18]}$ and at high concentrations, it may likely inactivate MMPs by enzyme denaturation rather than by chelation of cation. ${ }^{[10]}$ In vitro ${ }^{[19]}$ and in vivo ${ }^{[20]}$ studies have shown that $\mathrm{CHX}$ has a beneficial effect on the preservation of dentin-resin bonds. The use of CHX (0.12\%) mouthwash to rub on the preparation might seem to be the most immediate way to treat self-etch dentin bonds. Since CHX (0.12\%) (Peridex, 3M, USA) has a routine use in dental offices and for dentistry patients, we decided to use this $\mathrm{CHX}$ concentration applying it before bonding in etch-and-rinse adhesives. ${ }^{[1]}$

According to this study, amounts of bond strength in CHX group (Group C) (with and without thermocycling) were less than control group (Group A) but did not have statistically significant differences. This is showing that using of CHX $(0.12 \%)$ after acid etching in SB 2 adhesive has no effect on bond strength. This is hit off Soaresc's study. ${ }^{[21]}$

The zinc ion has also an inhibitory effect on the MMP activation, in a manner similar to $\mathrm{CHX}$. By increasing the amount of $\mathrm{Zn}$ ion, binding sites are

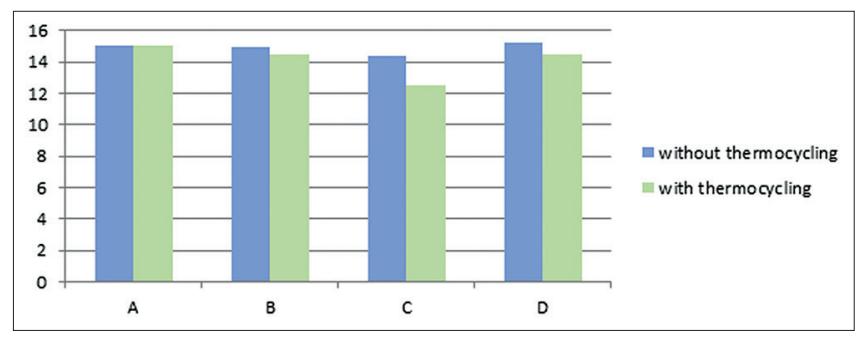

Figure 1: Comparison between microshear bond strength of groups with and without thermocycling

\begin{tabular}{|c|c|c|c|c|c|c|c|c|c|c|}
\hline \multirow[t]{2}{*}{ Group } & \multicolumn{2}{|c|}{ Cohesive dentin } & \multicolumn{2}{|c|}{$\begin{array}{c}\text { Cohesive } \\
\text { composite }\end{array}$} & \multicolumn{2}{|c|}{ Adhesive } & \multicolumn{2}{|c|}{ Mix } & \multicolumn{2}{|c|}{ Significant level } \\
\hline & 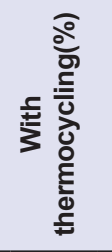 & 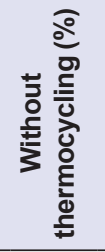 & 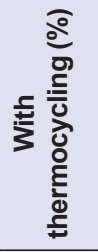 & 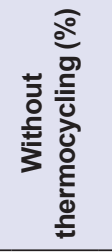 & 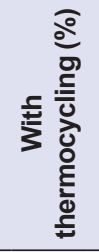 & 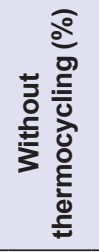 & 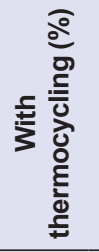 & 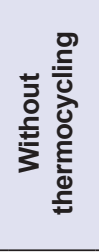 & 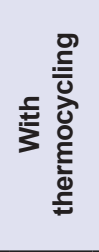 & 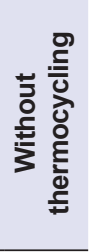 \\
\hline A & $15(75)$ & $11(55)$ & $5(25)$ & $5(25)$ & 0 & $2(10)$ & 0 & $2(10)$ & 0.062 & 0.181 \\
\hline B & $8(40)$ & $6(30)$ & $9(45)$ & $12(60)$ & $1(5)$ & 0 & 2 (10) & $2(10)$ & & \\
\hline C & $6(30)$ & $12(60)$ & $7(35)$ & $6(30)$ & $4(20)$ & 0 & $3(15)$ & $2(10)$ & & \\
\hline D & $8(40)$ & $9(45)$ & $5(25)$ & $10(50)$ & $5(25)$ & 0 & $2(10)$ & $1(5)$ & & \\
\hline
\end{tabular}

A: Control group, B: Nano zinc oxide group, C: Chlorhexidine group, D: Nano zinc oxide+chlorhexidine 
occupied by zinc, resulting in the spatial deformation and finally inhibiting MMP activity. A determining factor in the efficacy of nanoparticles in improving microshear bond strength is their dispersion quality in the matrices. A proper distribution of $\mathrm{ZnO}$ element is observed in the Map-EDX [Figure 2], which is an indicator of relatively homogeneous distribution of the NZO in the adhesive.

Osorio et al. ${ }^{[12]}$ evaluated the collagen degradation and bond strengths using SB adhesive containing NZO (etch-and-rinse) versus Clearfil self-etching primer (self-etch adhesive) for $24 \mathrm{~h}$ and 1 and 4 weeks, concluding that $\mathrm{Zn}$-doping of SB resin inhibited and stabilized collagen degradation at the hybrid layer (up to 4 weeks) and did not affect 24 -h bond strength, but increased bond stability of SB after 3 months. In the Osorio's study, dentin beam was immersed for $8 \mathrm{~h}$ in a zinc-containing resin bonding agent. In this study, we applied NZO-containing bonding agent according to the manufacturer's instructions to simulate the clinical steps.

$\mathrm{ZnO}$ is an amphoteric oxide although it normally exhibits basic properties. It is nearly insoluble in water and alcohol but is soluble in and degraded by acids. Small size particles of $\mathrm{ZnO}$ were selected to induce the highest interfibrillar infiltration. The high solubility of $\mathrm{ZnO}$ when combined with acid could also account for the effective release of zinc ions at the resin-dentin interface. ${ }^{[12]}$

In this study, bond strength in group with $\mathrm{ZnO}$ especially with thermocycling was a little better than group with $\mathrm{CHX}$ that was showing using of $\mathrm{ZnO}$ had no effect on bond strength. Nevertheless because $\mathrm{ZnO}$

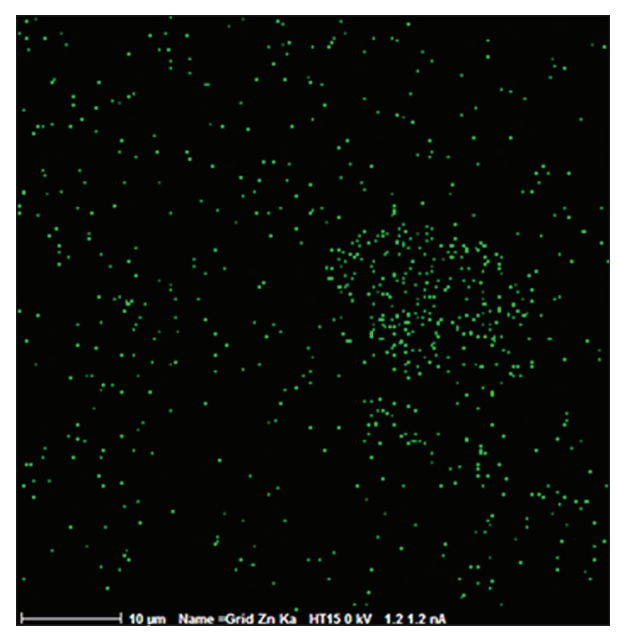

Figure 2: The Map-energy dispersive X-ray of cured adhesive containing $10 \mathrm{wt} \%$ of nano zinc oxide, which indicates a relatively homogeneous distribution of nano zinc oxide in the adhesive was added to SB 2 adhesive, Group $\mathrm{B}$ (with $\mathrm{ZnO}$ ) had clinically working steps less than $\mathrm{CHX}$ group that this is better.

Thermocycling is one broadly used artificial aging methodology, and in this study, we evaluated the effect of aging on the long-term performance of the bond; half of the samples were thermocycled and the other half was not. The results indicated no significant differences between the above circumstances.

Some studies have shown that during thermocycling, the specimens are subjected to thermal changes and also additional exposure to water. ${ }^{[22,23]}$ Thermal stresses generate mechanical stresses by differences in the coefficient of thermal expansion ${ }^{[23]}$ and can result in bond failure at the tooth-restoration interface. The main cause for the reduction in bond strength is believed to be the possible effect of hydrolysis at bonding interfaces. ${ }^{[23]}$ Consistent with a study by Titley et al., ${ }^{[24]}$ our study indicated that the shear bond strength of SB was not significantly affected by thermocycling. The positive effect of CHX and NZO separately and simultaneously on the microshear bond strength did not result in a decrease in bond strength after thermocycling. In the evaluation of failure, cohesive failure was dominant in all the groups. The cohesive failures of bonding agents are often associated with high bond strength values, indicating effective bonding. ${ }^{[25]}$ These findings are in line with the fact that thermocycling has no deleterious effect on the bond strength.

Various studies ${ }^{[26,27]}$ have suggested that acid etching is one way of activation of MMPs. Mazzoni et al. ${ }^{[28]}$ in a study with conflicting results stated that high acidity of phosphoric acid might lead to denaturation of the MMPs. Perhaps, that is why the use of CHX and NZO before and after thermocycling had no effect on the microshear bond strength. It is advised to investigate $\mathrm{CHX}$ with more concentration and NZO simultaneously in a fifth-generation adhesive for more evaluation.

\section{CONCLUSION}

Pretreatment with NZO and CHX separately and simultaneously did not affect microshear bond strength of SB 2.

\section{Acknowledgments}

We would like to thank Dental Materials Researches Center and Research Council of Babol University of Medical Sciences. 


\section{Financial support and sponsorship}

Nil.

\section{Conflicts of interest}

There are no conflicts of interest.

\section{REFERENCES}

1. Boruziniat A, Babazadeh M, Gifani M. Effect of chlorhexidine application on bond durability of a filled-adhesive system. J Dent Mater Tech 2013;2:6-10.

2. Suryakumari NB, Reddy PS, Surender LR, Kiran R. In vitro evaluation of influence of salivary contamination on the dentin bond strength of one-bottle adhesive systems. Contemp Clin Dent 2011;2:160-4.

3. Chaharom ME, Ajami AA, Kimyai S, Abbasi A. Effect of chlorhexidine on the shear bond strength of self-etch adhesives to dentin. Afr J Biotechnol 2011;10:10054-7.

4. Shafiei F, Memarpour M. Antibacterial activity in adhesive dentistry: A literature review. Gen Dent 2012;60:e346-56.

5. Elkassas DW, Fawzi EM, El Zohairy A. The effect of cavity disinfectants on the micro-shear bond strength of dentin adhesives. Eur J Dent 2014;8:184-90.

6. Indira MD, Nandlal B. Comparative evaluation of the effect of cavity disinfectants on the fracture resistance of primary molars restored with indirect composite inlays: An in vitro study. J Indian Soc Pedod Prev Dent 2010;28:258-63.

7. Moon PC, Weaver J, Brooks CN. Review of matrix metalloproteinases' effect on the hybrid dentin bond layer stability and chlorhexidine clinical use to prevent bond failure. Open Dent J 2010;4:147-52.

8. Osorio R, Yamauti M, Osorio E, Ruiz-Requena ME, Pashley D, Tay $\mathrm{F}$, et al. Effect of dentin etching and chlorhexidine application on metalloproteinase-mediated collagen degradation. Eur J Oral Sci 2011;119:79-85

9. Spencer P, Ye Q, Park J, Topp EM, Misra A, Marangos O, et al. Adhesive/dentin interface: The weak link in the composite restoration. Ann Biomed Eng 2010;38:1989-2003.

10. Komori PC, Pashley DH, Tjäderhane L, Breschi L, Mazzoni A, de Goes MF, et al. Effect of $2 \%$ chlorhexidine digluconate on the bond strength to normal versus caries-affected dentin. Oper Dent 2009;34:157-65.

11. Alaghemand H, Esmaeili B, Firouz P, Soltani M, Rouhaninasab M, Bijani A. A comparative study of the preventive effect of chlorhexidine o. $12 \%$ and nano zinc oxide particles on the distraction of collagen scaffolding of the hybrid layer by two immunohistochemistry and microleakage tests. Dent Med Res 2014;2:33-8.

12. Osorio R, Yamauti M, Osorio E, Román JS, Toledano M. Zinc-doped dentin adhesive for collagen protection at the hybrid layer. Eur J Oral
Sci 2011;119:401-10.

13. Leitune VC, Portella FF, Bohn PV, Collares FM, Samuel SM. Influence of chlorhexidine application on longitudinal adhesive bond strength in deciduous teeth. Braz Oral Res 2011;25:388-92.

14. Sadek FT, Braga RR, Muench A, Liu Y, Pashley DH, Tay FR. Ethanol wet-bonding challenges current anti-degradation strategy. J Dent Res 2010;89:1499-504.

15. Pupo YM, Michél MD, Gomes OM, Lepienski CM, Gomes IC. Effect of the regional variability of dentinal substrate and modes of application of adhesive systems on the mechanical properties of the adhesive layer. J Conserv Dent 2012;15:132-6.

16. Singh H, Kapoor P, Dhillon J, Kaur M. Evaluation of three different concentrations of chlorhexidine for their substantivity to human dentin. Indian J Dent 2014;5:199-201.

17. Carrilho MR, Carvalho RM, Sousa EN, Nicolau J, Breschi L, Mazzoni A, et al. Substantivity of chlorhexidine to human dentin. Dent Mater 2010;26:779-85.

18. Gendron R, Grenier D, Sorsa T, Mayrand D. Inhibition of the activities of matrix metalloproteinases 2, 8, and 9 by chlorhexidine. Clin Diagn Lab Immunol 1999;6:437-9.

19. Pashley DH, Tay FR, Yiu C, Hashimoto M, Breschi L, Carvalho RM, et al. Collagen degradation by host-derived enzymes during aging. J Dent Res 2004;83:216-21.

20. Brackett MG, Tay FR, Brackett WW, Dib A, Dipp FA, Mai S, et al. In vivo chlorhexidine stabilization of hybrid layers of an acetone-based dentin adhesive. Oper Dent 2009;34:379-83.

21. Soares C, Pereira C, Pereira J, Santana F, Prado C. Effect of chlorhexidine application on microtensile bond strength to dentin. Operative dentistry 2008;33:183-8.

22. Elekdag-Turk S, Turk T, Isci D, Ozkalayci N. Thermocycling effects on shear bond strength of a self-etching primer. Angle Orthod 2008;78:351-6.

23. Korkmaz Y, Gurgan S, Firat E, Nathanson D. Effect of adhesives and thermocycling on the shear bond strength of a nano-composite to coronal and root dentin. Oper Dent 2010;35:522-9.

24. Titley K, Caldwell R, Kulkarni G. Factors that affect the shear bond strength of multiple component and single bottle adhesives to dentin. Am J Dent 2003;16:120-4.

25. Al-Hana DA, El-Messairy A, Shohayb F, Alhadainy H. Micro-shear bond strength of different composites and glass-ionomers used to reinforce root dentin. Tanta Dent J 2013;10:58-66.

26. Breschi L, Mazzoni A, Nato F, Carrilho M, Visintini E, Tjäderhane L, et al. Chlorhexidine stabilizes the adhesive interface: A 2-year in vitro study. Dent Mater 2010;26:320-5.

27. De Munck J, Van den Steen PE, Mine A, Van Landuyt KL, Poitevin A, Opdenakker $G$, et al. Inhibition of enzymatic degradation of adhesive-dentin interfaces. J Dent Res 2009;88:1101-6.

28. Mazzoni A, Pashley DH, Nishitani Y, Breschi L, Mannello F, Tjäderhane L, et al. Reactivation of inactivated endogenous proteolytic activities in phosphoric acid-etched dentine by etch-and-rinse adhesives. Biomaterials 2006;27:4470-6. 